\title{
Flaked stone assemblage variability across the Weipa region of western Cape York Peninsula, Queensland
}

\author{
Justin Shiner ${ }^{\mathrm{a}}$, Simon Holdaway ${ }^{\mathrm{a}^{*}}$ and Patricia Fanning ${ }^{\mathrm{b}}$ \\ a Anthropology, School of Social Sciences, The University of Auckland, Private Bag 92019, Auckland 1142, New Zealand; \\ ${ }^{\mathrm{b}}$ Department of Environmental Sciences, Macquarie University, NSW 2109, Australia \\ * Corresponding author sj.holdaway@auckland.ac.nz
}

\begin{abstract}
Shell mounds located on the coastal and estuarine fringes are the best-known archaeological feature in the Weipa region, northwestern Cape York Peninsula, Australia. Other archaeological deposits have received less attention, with stone artefacts thought to be all but absent reflecting the lack of raw material suitable for flaking in the region. Cultural heritage surveys on the bauxite plateau in the Weipa region undertaken since 2003 have changed this view. Here we report on stone artefacts manufactured from quartz, quartzite, silcrete, and mudstone. Surprisingly, flakes and cores in assemblages from across the surveyed region retain a relatively large proportion of cortex, indicating limited lithic reduction despite the lack of local raw material. Comparisons made with assemblage characteristics from other regions in Australia indicate that this lack of core reduction may reflect use of the Albatross Bay landscape by people who were confident of being able to access the lithic sources outside the region to replenish their tool kits.
\end{abstract}

\section{Introduction}

The archaeology of the Weipa area on the northwestern coast of Cape York Peninsula (Figure 1) is most often associated with the many shell mounds found throughout the river estuaries of Albatross Bay. These features have dominated archaeological investigation in the region for the last 40 years (Bailey 1975, 1977, 1999; Cribb 1986; Holdaway et al. 2017; Morrison 2003, 2010; Shiner et al. 2013; Wright 1971). In a landscape that does not contain rockshelters, the shell mounds offer the opportunity to investigate not only temporal patterns in coastal resource use, but also human responses to environmental change (e.g. Holdaway et al. 2017; Shiner et al. 2013). While other aspects of the archaeological record in the Weipa area received less attention in the past, this is changing because of the cultural heritage surveys conducted prior to bauxite mining (Shiner and Morrison 2009).

In 2003, an annual programme of large-scale, systematic, cultural heritage surveys commenced on bauxite mining tenements around the Weipa area. The surveys focused on the bauxite plateau and drainage channels, two areas underrepresented in earlier archaeological investigations. These surveys documented surface deposits of stone artefacts, scarred trees, earthen mounds, and historic sites (Barkley et al. 2009; Morrison et al. 2010; Shiner and Morrison 2009). The discovery of quantities of stone artefacts was unexpected as earlier studies concluded that stone artefacts were rare or unimportant in pre-contact, western Cape York with technologies focussed on perishable materials (e.g. Sutton 1994). Furthermore, geological data indicated that the bauxite plateau was a lithic-poor environment with virtually no suitable stone sources for flaking. Here we report on the analyses of stone artefact scatters identified through systematic survey.

To help understand the nature of stone raw material procurement and differential use of the region, the analyses presented here make use of three arbitrary geographic subregions based on the dissection of the Weipa bauxite plateau by major rivers flowing into the Gulf of Carpentaria at Albatross Bay (Figure 1). The southern assemblage is composed of artefacts from the Weipa Peninsula between the
Mission and Embley Rivers. The central assemblage covers the Andoom Peninsula from the north bank of the Mission River to the south bank of the Wenlock River, and the northern assemblage extends from the north bank of the Wenlock to the area around the Skardon River (Figure 2). While such a division is indeed arbitrary with all three subregions having similar present day environments, it does allow the investigation of geographic variation in assemblage composition across the region as a whole. We present initial results based on these areas searching for variation that may form the basis for future research.

\section{Cultural Heritage Survey and Artefact Recording at Weipa}

The Weipa region, adjacent to Albatross Bay on the western side of Cape York Peninsula, is approximately $800 \mathrm{~km}$ northwest of Cairns in far north Queensland (Figure 1). The bauxite-capped plateau is the focus of bauxite mining, with a bauxite layer between $1 \mathrm{~m}$ and $10 \mathrm{~m}$ thick occurring approximately $1 \mathrm{~m}$ below the topsoil. Eucalypt open woodland dominated by the Darwin Stringybark (Eucalyptus tetrodonta) and several other minor species covers the relatively flat plateau. Topographic relief occurs in the shallow gullies associated with drainage around the plateau margins. Prior to 2003, knowledge of stone artefacts was restricted to the few artefacts seen on the surface of shell mounds or recovered during excavation with descriptions largely limited to raw material type and artefact form (e.g. Bailey 1977). While the quantities of stone artefacts were small, Bailey (1993) suggested that the density of artefacts recovered during the Kwamter excavation indicated that the entire mound might contain around 19,500 artefacts. Subsequent excavations of shell mounds across the Weipa area were not extensive enough to verify this estimate recovering only small numbers of artefacts (e.g. Morrison 2010).

Since 2003, systematic archaeological survey of potential mining and conservation areas covering both the bauxite plateau and riverine corridors has revealed previously unrecognised surface distributions of stone artefacts as well 


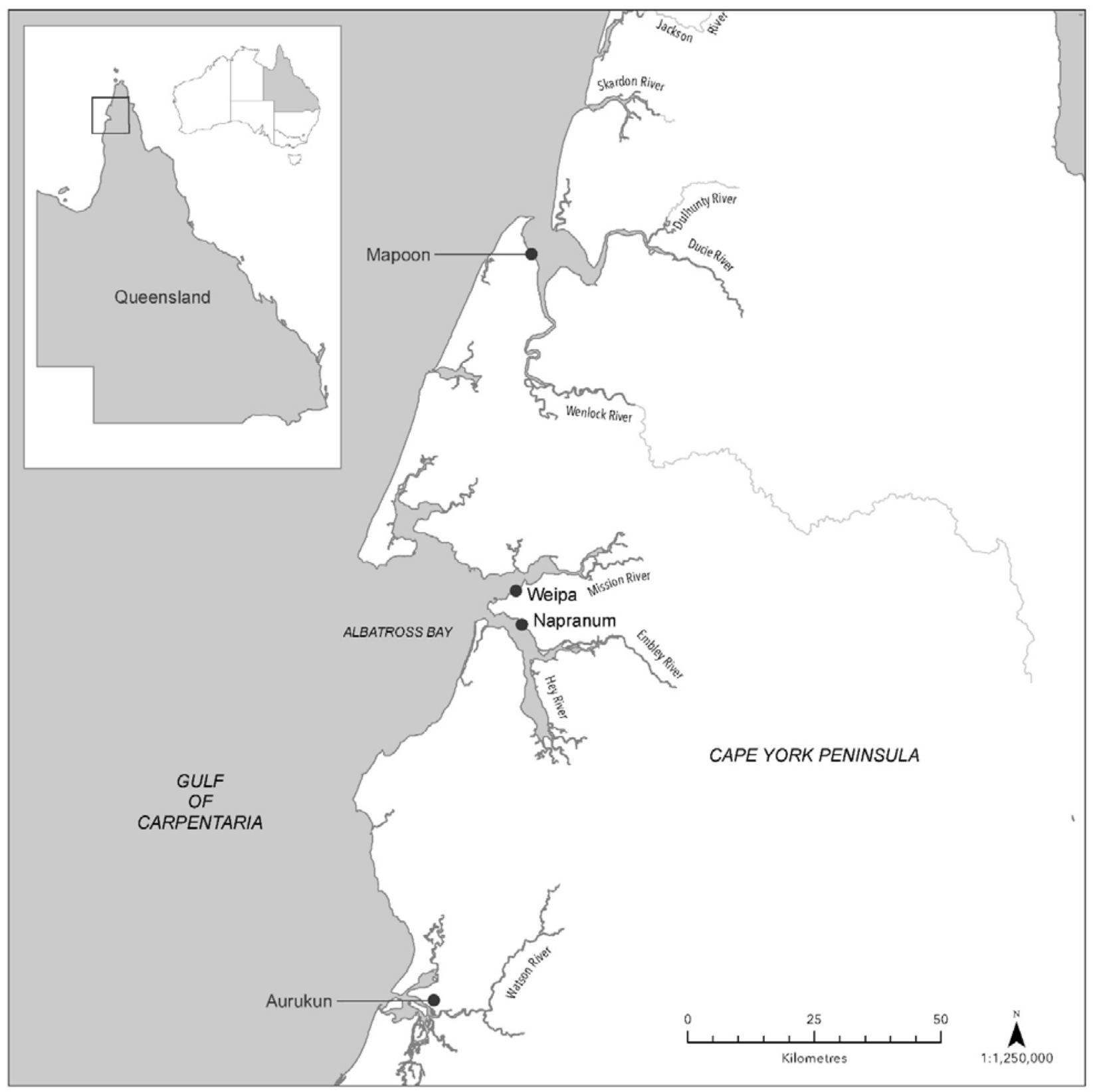

Figure 1. Weipa region of Cape York Peninsula.

Table 1. Distribution of stone artefacts across the three survey subregions.

\begin{tabular}{|l|l|l|l|}
\hline & Northern & Central & Southern \\
\hline Total stone artefacts & 1242 & 2647 & 2327 \\
\hline $\begin{array}{l}\text { Within 300m of a creek, swamp } \\
\text { or riverine corridor }\end{array}$ & $\begin{array}{l}1238 \\
(99.7 \%)\end{array}$ & $\begin{array}{l}2576 \\
(97.3 \%)\end{array}$ & $\begin{array}{l}2070 \\
(89 \%)\end{array}$ \\
\hline Bauxite Plateau & 4 & 71 & 257 \\
$(0.3 \%)$ & $(2.7 \%)$ & $71 \%)$ \\
\hline $\begin{array}{l}\text { Number of locations with stone } \\
\text { artefacts }\end{array}$ & 42 & 52 & 78 \\
\hline $\begin{array}{l}\text { Average number of stone } \\
\text { artefacts per location }\end{array}$ & 29.6 & 50.9 & 29.8 \\
\hline
\end{tabular}




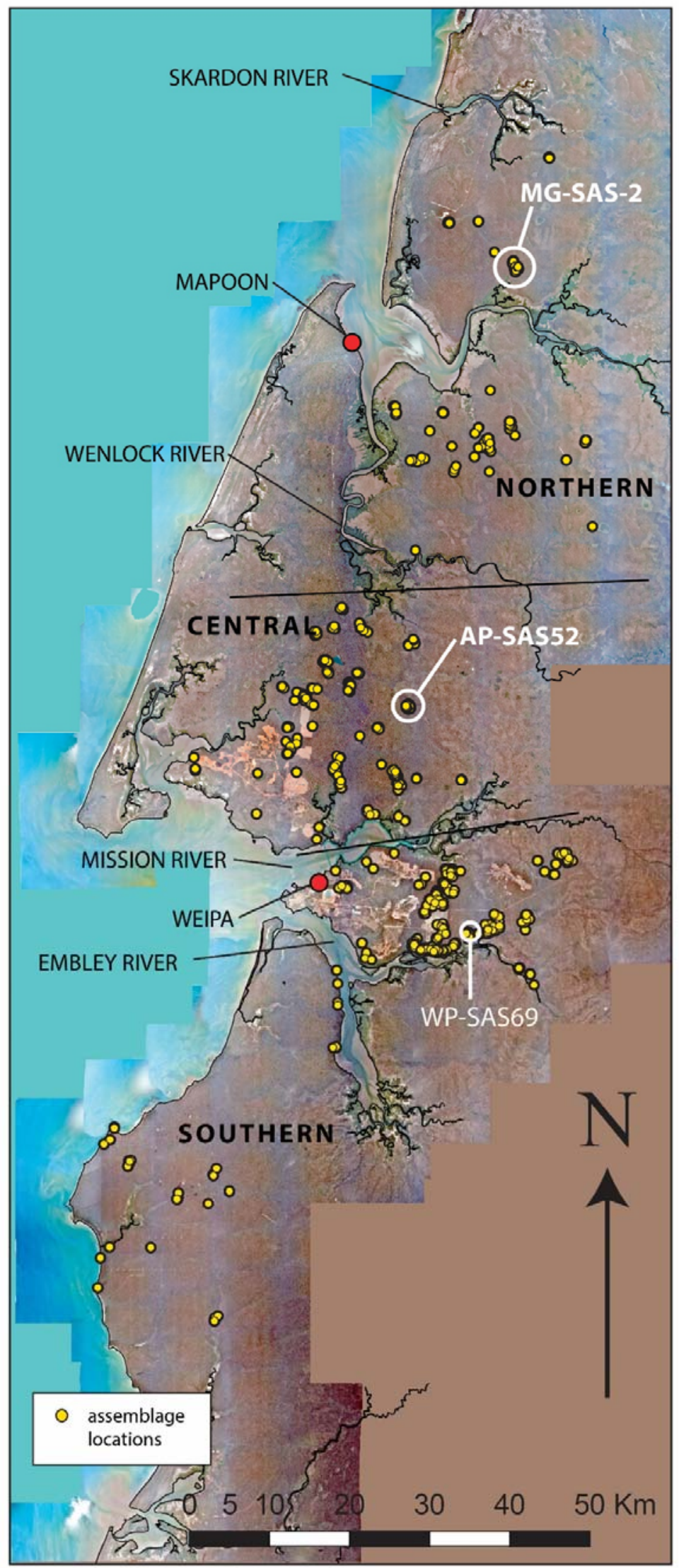

Figure 2. Distribution of stone artefact assemblages across the study area (yellow dots) highlighting the three largest assemblages in the survey subregions (data and aerial photograph background courtesy of Rio Tinto). 
as culturally modified trees. Based solely on numbers, it is these site types rather than shell mounds that are the most common on the bauxite plateau, with shell and earth mounds limited in their distribution to areas at the intersection of the bauxite plateau and the estuarine margins. Over 150 separate locations with stone artefacts are now known across the bauxite plateau near Weipa (Figure 2) indicating that regions inland from the river estuaries were in use (Shiner and Morrison 2009).

During cultural heritage surveys, intensive pedestrian survey occurred in areas surrounding initial stone artefact find spots, with the extent of the area investigated determined by surface visibility and underlying surface type (e.g. ironstone on the bauxite plateau and black soil associated with swamps). The individual locations of artefacts encountered during these surveys were noted and technological attributes along with dimensions, following the definitions in Holdaway and Stern (2004), were recorded.

The ability to identify surface stone artefacts at Weipa varies between the wet and dry seasons, as surface visibility is affected by the dense vegetation understorey that grows during the wet season. Dry season fires that burn the thick grass create optimum conditions for surface visibility although these are often limited in spatial extent and dense near surface debris including topsoil often limits visibility. As a consequence, stone artefacts are only recognised in two distinct contexts, either on exposed ironstone gravel slopes along the margins of creeks (Figure 3 ) or around the margins of inland paperbark swamps (Table 1). Documented occurrences of stone artefacts are therefore rare on the bauxite plateau itself, where ironstone surfaces are uncommon, with the exception of areas where higher relief has combined with erosion to expose the bauxite gravels underlying the topsoil layer. The potential for buried deposits containing artefacts therefore exists on the bauxite plateau itself, especially in the immediate vicinity of such eroded areas. However, a lack of topographic features that might concentrate past human behaviour in any one location makes prediction of where these surfaces and therefore artefact scatters might occur difficult. As well, the constant bioturbation that occurs on the bauxite plateau may act to obscure artefacts discarded on the plateau surface. Eggleton and Taylor (2008) estimate that each hectare of the bauxite plateau is completely bioturbated every 20,000 years due to tree fall, tree root displacement, and termite activity. They also note how in a 1 ha area, tree fall lifted $4.1 \mathrm{~m}^{3}$ of regolith and disturbed an area of $56 \mathrm{~m}^{2}$. These factors limit the ability to undertake a comprehensive survey for stone artefacts with recording dependent on locations where visibility allows it. The results of the systematic survey discussed here therefore document stone artefacts that were visible in the areas surveyed rather than all the artefacts that were potentially present. Systematic recording allowed us to document a relatively large number of stone artefacts in total but we cannot be sure how many more artefacts remain buried or otherwise obscured. In obtaining the results that follow, we have therefore adopted the use of analyses that focus on identifying general patterns. Obviously the results should be viewed as preliminary, and any patterns identified will need to be further examined in future work.

For these reasons as well as the small numbers of artefacts recorded at each individual location, in the following, three subregional sets combine the artefacts identified at individual locations permitting the analysis of patterning present at a regional level. We refer to assemblages rather than sites in the ensuing discussions because it seems likely that the boundaries around artefact scatters reflect contemporary visibility rather than any occupational extent. It is not possible to date either individual stone artefacts or the surface scatters which form assemblages, therefore analyses report spatial patterning of technological attributes rather than patterns based on chronology.

More than $90 \%$ of stone artefacts at Weipa were analysed by one observer (JS) according to the recording protocols established by the Western New South Wales Archaeology Program (WNSWAP) (Holdaway et al. 2005; Shiner 2008; Shiner et al. 2005, 2007). The remaining proportion were analysed by Rio Tinto heritage staff trained by JS or by a small pool of consultant archaeologists using the same protocols. This reduces the impact of inter-observer bias although we did not assess this quantitatively.

\section{Results}

The mean assemblage size for the surface stone artefacts is 50 artefacts or less, with the largest, single assemblage consisting of 515 artefacts. The assemblages are also relatively low in density, with few areas of concentrated knapping debris (Table 1). Within each of the subregions, the largest assemblages from a single location are Northern MG-SAS2 with 286 artefacts, Central AP-SAS52 with 492 artefacts, and Southern WP-SAS69 with 515 artefacts. These single locations represent approximately one-fifth of the total number of stone artefacts from each of the three subregions considered here.

Sources of stone suitable for stone artefact manufacture are largely absent from the bauxite plateau. Exceptions include small (golf-ball size and shape) quartz nodules with cortex that is smooth that occur in isolated areas on the eastern side of the Weipa Peninsula bauxite plateau where the underlying sediments of the Bulimba Formation are exposed along creek margins. While they form a potential local raw material source, they are often of poor quality for stone artefact manufacture since they contain numerous natural fracture planes. Small numbers of silcrete cortical nodules occur in the beds of creeks in the Embley Range, east of the bauxite plateau. However, the frequency and location of these nodules is difficult to predict since they are transported downstream from their source as part of the bed load of the creeks limiting their utility as a raw material source. Mudstone and quartzite do not occur naturally on the bauxite plateau - they were most likely carried in or potentially obtained by trade and exchange from locations in the rangelands further to the east together with quartz and silcrete nodules of a better quality for flaking.

Artefact raw material proportions based on the Number of Artefact Specimens (NAS, after Hiscock 2002) indicates a similar pattern of raw material representation in the central and southern assemblages, with quartz the dominant raw material and silcrete the second most common (Table 2). In the northern subregion, however, mudstone is the most common raw material followed by quartz and then silcrete. Mudstone is a minor component of assemblages in the central and southern assemblages. Proportions calculated using the Minimum Number of Flakes (MNF) differ from those calculated by NAS by less than $4 \%$, and are therefore not reported. 


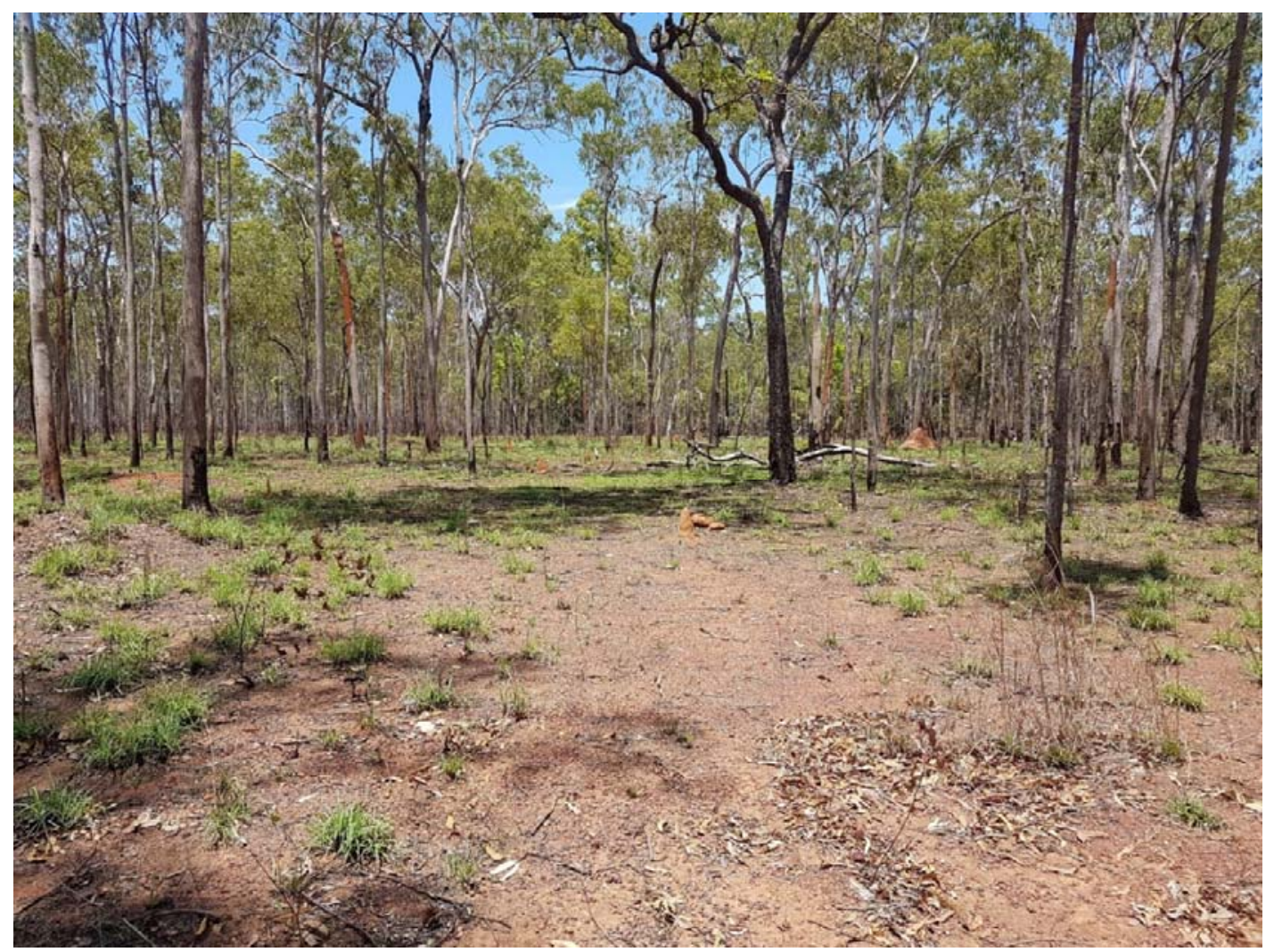

Figure 3. Exposed ironstone gravel deposit. Surfaces such as this expose stone artefacts (Photograph: Justin Shiner).

Table 2. Raw material proportions across the three subregions, calculated by summing the numbers of artefacts (i.e. number of artefactual specimens) of each material type in assemblages in each of the subregions.

\begin{tabular}{|l|l|l|l|}
\hline Raw Material & \multicolumn{1}{|c|}{ Northern } & \multicolumn{1}{|c|}{ Central } & \multicolumn{1}{|c|}{ Southern } \\
\hline Mudstone & $466(37.5 \%)$ & $98(3.7 \%)$ & $17(0.7 \%)$ \\
\hline Quartz & $457(36.8 \%)$ & $1728(65.3 \%)$ & $1494(64.2 \%)$ \\
\hline Quartzite & $91(7.3 \%)$ & $37(1.4 \%)$ & $41(1.8 \%)$ \\
\hline Silcrete & $212(17.1 \%)$ & $765(28.9 \%)$ & $732(31.5 \%)$ \\
\hline Other & $16(1.3 \%)$ & $19(0.7 \%)$ & $43(1.8 \%)$ \\
\hline Total & 1242 & 2647 & 2327 \\
\hline
\end{tabular}

Table 3. Flake to core ratios, mean maximum core scar length, and mean maximum core length across the three subregions for the three main raw material types. Mudstone core numbers were too low to permit calculations. All dimensions are given in millimetres.

\begin{tabular}{|l|l|l|l|l|}
\hline Subregion & \multicolumn{1}{|c|}{ Measure } & Mudstone & \multicolumn{1}{c|}{ Quartz } & \multicolumn{1}{c|}{ Silcrete } \\
\hline \multirow{4}{*}{ Northern } & Flake to core ratio & 7.1 & 4.1 & 4.6 \\
\cline { 2 - 5 } & Core scar maximum length & & $15 \pm 4.4(44)$ & $24 \pm 11(9)$ \\
\cline { 2 - 5 } & Core maximum length & & $31 \pm 8(44)$ & $53.9 \pm 20.4(25)$ \\
\cline { 2 - 5 } & Complete flake length & & $18.4 \pm 5.9(147)$ & $29.8 \pm 9.8(98)$ \\
\hline \multirow{4}{*}{ Central } & Flake to core ratio & 9.4 & 9.2 & 9.4 \\
\cline { 2 - 5 } & Core scar maximum length & & $14.2 \pm 5.3(83)$ & $21.8 \pm 11.8(41)$ \\
\cline { 2 - 5 } & Core maximum length & & $28.5 \pm 7.5(77)$ & $51.1 \pm 22.5(41)$ \\
\cline { 2 - 5 } & Complete flake length & & $16.9 \pm 5.2(521)$ & $23.6 \pm 9.5(287)$ \\
\hline \multirow{5}{*}{ Southern } & Flake to core ratio & 2.3 & 2.2 & 3.4 \\
\cline { 2 - 5 } & Core scar maximum length & & $15.9 \pm 5.3(226)$ & $24.8 \pm 12.6(79)$ \\
\cline { 2 - 5 } & Core maximum length & & $32 \pm 7.5(32)$ & $63.3 \pm 26.3(83)$ \\
\cline { 2 - 5 } & Complete flake length & & $18.5 \pm 6.3(404)$ & $32.7 \pm 13.2(223)$ \\
\hline
\end{tabular}


Table 4. Cortex frequency and proportions for mudstone, quartz and silcrete cores and non-cortical to cortical complete flake ratios in the three subregions.

\begin{tabular}{|c|l|c|l|l|}
\hline Subregion & \multicolumn{1}{|c|}{ Cortex } & Mudstone & Quartz & \multicolumn{1}{c|}{ Silcrete } \\
\hline \multirow{5}{*}{ Northern } & None & $3(30 \%)$ & $1(1.6 \%)$ & $6(24 \%)$ \\
\cline { 2 - 5 } & $1-50 \%$ & $1(10 \%)$ & $33(51.6 \%)$ & $15(60 \%)$ \\
\cline { 2 - 5 } & $50-99 \%$ & $6(60 \%)$ & $30(46.9 \%)$ & $4(16 \%)$ \\
\cline { 2 - 5 } & $\begin{array}{l}\text { Non-cortical to cortical } \\
\text { complete flake ratio }\end{array}$ & 1.2 & 0.5 & 2 \\
\hline \multirow{5}{*}{ Central } & None & $2(40 \%)$ & $7(5.8 \%)$ & $19(46.3 \%)$ \\
\cline { 2 - 5 } & $1-50 \%$ & $3(60 \%)$ & $67(55.4 \%)$ & $12(29.3 \%)$ \\
\cline { 2 - 5 } & $50-99 \%$ & & $47(38.8 \%)$ & $10(24.4 \%)$ \\
\cline { 2 - 5 } & $\begin{array}{l}\text { Non-cortical to cortical } \\
\text { complete flake ratio }\end{array}$ & 3.2 & 0.4 & 2.4 \\
\hline \multirow{5}{*}{ Southern } & None & & $13(4.5 \%)$ & $27(32.5 \%)$ \\
\cline { 2 - 5 } & $1-50 \%$ & & $135(46.9 \%)$ & $40(48.2 \%)$ \\
\cline { 2 - 5 } & $50-99 \%$ & NA & 0.4 & $16(19.3 \%)$ \\
\cline { 2 - 5 } & $\begin{array}{l}\text { Non-cortical to cortical } \\
\text { complete flake ratio }\end{array}$ & & & 1.1 \\
\hline
\end{tabular}

Table 5. Cortex ratio values for the three most common raw materials using all of the Weipa assemblages. Flake volume relative to mean core volume expressed as number of core equivalents; core and flake volume proportions; and number of cores recorded.

\begin{tabular}{|l|l|l|l|}
\hline & Mudstone & \multicolumn{1}{|c|}{ Quartz } & Silcrete \\
\hline Cortex ratio & 0.81 & 0.80 & 0.55 \\
\hline Flake volume relative to mean core volume & 15.11 & 130.17 & 29.50 \\
\hline Core and flake volume proportions & $74 \% / 26 \%$ & $81 \% / 19 \%$ & $85 \% / 15 \%$ \\
\hline Core number & 41 & 566 & 165 \\
\hline
\end{tabular}

There are differences in the ratio of flakes to cores between the three subregions, when calculated for the most abundant raw materials (Table 3). However, within each subregion, the ratios are similar irrespective of raw material type, suggesting a consistent level of reduction intensity. The lowest number of flakes per core occurs in the southern subregion and the highest occurs in the central subregion. The southern subregion also shows the largest core scar lengths for quartz and silcrete (see Table 3 - mudstone numbers were too low to calculate) while the central subregion has the smallest, average, scar lengths, and the smallest maximum core sizes. The central assemblage also has smaller flakes than those from the other subregions while the southern assemblage has the largest flakes (Table 3). The significance of these differences is of course difficult to assess given that the subregions were arbitrarily defined. They provide an indication that subregional variability may exist but will need to be explored further in future work.

A majority of cores retain some cortex irrespective of raw material type (Table 4). Quartz cores are the most cortical with only small proportions retaining no cortex at all and, interestingly, even the more intensively worked silcrete cores, as measured by the flake to core ratio, often retain some cortex. Half of the mudstone cores retain cortex despite the rarity of cores made from this raw material. There are more cortical quartz flakes than non-cortical flakes and the noncortical to cortical flake ratios for other raw materials are all less than the 3.2:1 ratio for central subregion mudstone. These results indicate that, across the three subregions, the central subregion has higher values for both the flake to core and noncortical to cortical flake ratios suggesting that, in this subregion, core reduction was more intensive than in the other subregions.

Measures of cortex abundance support the more intensive reduction of both quartz and silcrete cores in the central subregion. The quartz non-cortical to cortical flake ratio is the only exception, where the ratio (0.5) is slightly greater for the northern assemblages when compared to the central assemblage (0.4) (Table 4).

An alternative way of quantifying the relative abundance of cortical artefacts uses the cortex ratio (Dibble et al. 2005; Douglass et al. 2008). Calculation of the ratio involves comparing an estimate of the original surface area of the flaked cobbles covered with cortex to the cortical surface area of the cores added to the cortical surface area of the flakes. The resulting ratio compares the observed cortical surface area to that expected from the number of cobbles flaked as estimated by the number of cores. The ratio is based on geometric measures and therefore does not vary according to the way cores were flaked. If the ratio is equal to one, then all the products of flaking are present within the assemblage. If the ratio is greater than one then cortex was added while values less than one indicate that material was removed. Either addition or removal of material acts as a proxy for the 
movement of people who carried artefacts with them assuming no natural process can account for the addition or removal of artefacts with cortical surface area. In this way, the cortex ratio provides a global estimate of assemblage completeness dependent on the spatial area from which the assemblages derive, summarising the completeness of assemblages over the period they accumulated. The ratio therefore forms a useful proxy by which to assess long term movement into and out of regions although not necessarily within regions (Davies and Holdaway 2018).

In light of the issues related to visibility discussed above as well as the utility of the ratio as a proxy for movement, Table 5 reports the cortex ratio across all of the subregions combined for the three most common raw materials rather than results of the ratio calculated for each assemblage. At 0.8 , the values for both mudstone and quartz indicate that there is nearly enough cortex present on both the cores and the flakes in the same material to account for the cortical surface area that originally existed on the nodules that were flaked (i.e. 0.8 is close to 1.0). The results therefore suggest only limited movement of flakes away from the assemblages that were analysed. The value for the silcrete ratio is lower, indicating more movement of flakes away from the assemblages where they were found. Calculating core and flake volume indicates similar results (Phillipps and Holdaway 2016). The combined volume of flakes expressed as core equivalents using the mean volume of cores manufactured from each material indicates that the combined flake volume represents many fewer cores than the number recorded. In all three materials, the majority of volume rests in the cores (Table 5).

The locations to which the flakes that are missing were removed cannot be determined with the data available since we lack the ability to calculate ratio values at a range of smaller spatial scales. As noted above, stone artefacts in the Weipa region occur in small numbers, over spatially restricted areas limited by visibility. Therefore, while the results indicate material removal in the form of flakes from the vicinity of the cores especially for silcrete it is not possible to determine whether this was a local movement or involved greater distances. However, as with the analyses reported above, overall the cortex ratio and volume calculations show considerable unused potential remaining in the abandoned cores. This observation is important since it reflects on the socio-economy of landscape use particularly in relation to raw material transport as discussed further below. At some point in the future, it may be possible to obtain sufficient data to show how the cortex and volume ratio vary at a variety of subregional spatial scales as we have for the Rutherfords Creek data in western New South Wales (Davies and Holdaway 2018), however, this would require much more intensive work including excavation of near surface deposits on the bauxite plateau. Of course, the visibility issues discussed above would make this a challenging undertaking.

Artefacts with deliberate edge modification are uncommon in all of the subregions, accounting for less than $3 \%$ of all artefacts by NAS. The southern subregion has the highest overall proportion of retouched items, accounting for $2.1 \%$ of all artefacts compared with $1.5 \%$ and $1.4 \%$ respectively for the central and northern assemblages. These proportions are low, even in comparison with assemblages from western New South Wales where tools typically account for about $5 \%$ of all artefacts and assemblage descriptions emphasise low tool proportions (Douglass et al. 2017; Shiner et al. 2005). Scrapers with continuous and invasive edge modification account for the majority of retouched tools in the Weipa assemblages. These tools show edge modification across both the lateral margins and the distal end. However, few scrapers exhibit retouch on all available edges (i.e. edges excluding the proximal or platform end of the tool).

Other formal tool types are restricted to several backed blades and tula adze-like artefacts. Twenty-one edge-ground axes were recorded across all three subregions, with the largest number occurring in the southern subregion (Figure 4). Measurements are available for 19 of these, providing mean maximum length, width, and thickness of $85.8 \pm 19.3 \mathrm{~mm}$, $73.7 \pm 20.4 \mathrm{~mm}$, and $34.5 \pm 10.4 \mathrm{~mm}$. Nine of the axes are made from hornfels with others made from a variety of lithology. In addition, Morrison (2010) recorded seven edge-ground axes from the Weipa region held in the Queensland Museum. This tool type was once thought to be largely absent from areas adjacent to Weipa (Sutton 2010). No sources of stone suitable for the manufacture of edge-ground axes occur locally, with the nearest possible sources thought to occur in the Iron Range $120 \mathrm{~km}$ to the east (Bailey 1977).

\section{Discussion}

Stone artefacts manufactured from a variety of raw materials, most likely sourced from outside the Weipa region, are present in all three of the geographic subregions delineated by the major rivers running into Albatross Bay. The stone artefacts occur as low-density scatters, predominantly near watercourses, where the lack of surface cover allows for good visibility. Both cores and flakes retain relatively high proportions of cortex suggesting that core reduction did not continue to the point where cores were exhausted. Retouched tools are rare but edge-ground axes occur in such numbers to suggest they formed a component of the regional toolkit.

With the exception of Bailey's (1993) comment concerning the Kwamter shell mound, previous assessments of the Weipa region down-played the presence of stone artefacts, either focussing on shell mound survey and excavation (e.g. Bailey 1972; Cribb 1986; Morrison 2003) or relying on ethnographic and historical information to determine past landscape use (e.g. Sutton 1994, 2010). There are now more than 6,000 stone artefacts recorded from the Weipa region reflecting the recent implementation of intensive, systematic, landform-based survey. The results of these surveys demonstrate assemblage sizes of up to several hundred stone artefacts at some locations, often found isolated from other archaeological materials. Their presence away from the estuarine edges suggests a broader range of relationships between people and the environment than was formerly supposed with shell mounds considered alone.

Before the results of intensive, systematic surveys were available, the notion that stone artefacts played only a minor role in Aboriginal occupation of the Weipa area was perhaps not surprising because there were virtually no known local sources of raw material suitable for stone artefact manufacture. Without systematic survey, artefacts were also difficult to identify in forested environments where there is significant seasonal variability in surface visibility. The large numbers of stone artefacts now identified illustrates the advantage of undertaking systematic survey even in areas where archaeological materials are thought to be largely absent. It remains possible that even more stone artefacts remain as yet undocumented in areas that are not exposed. 

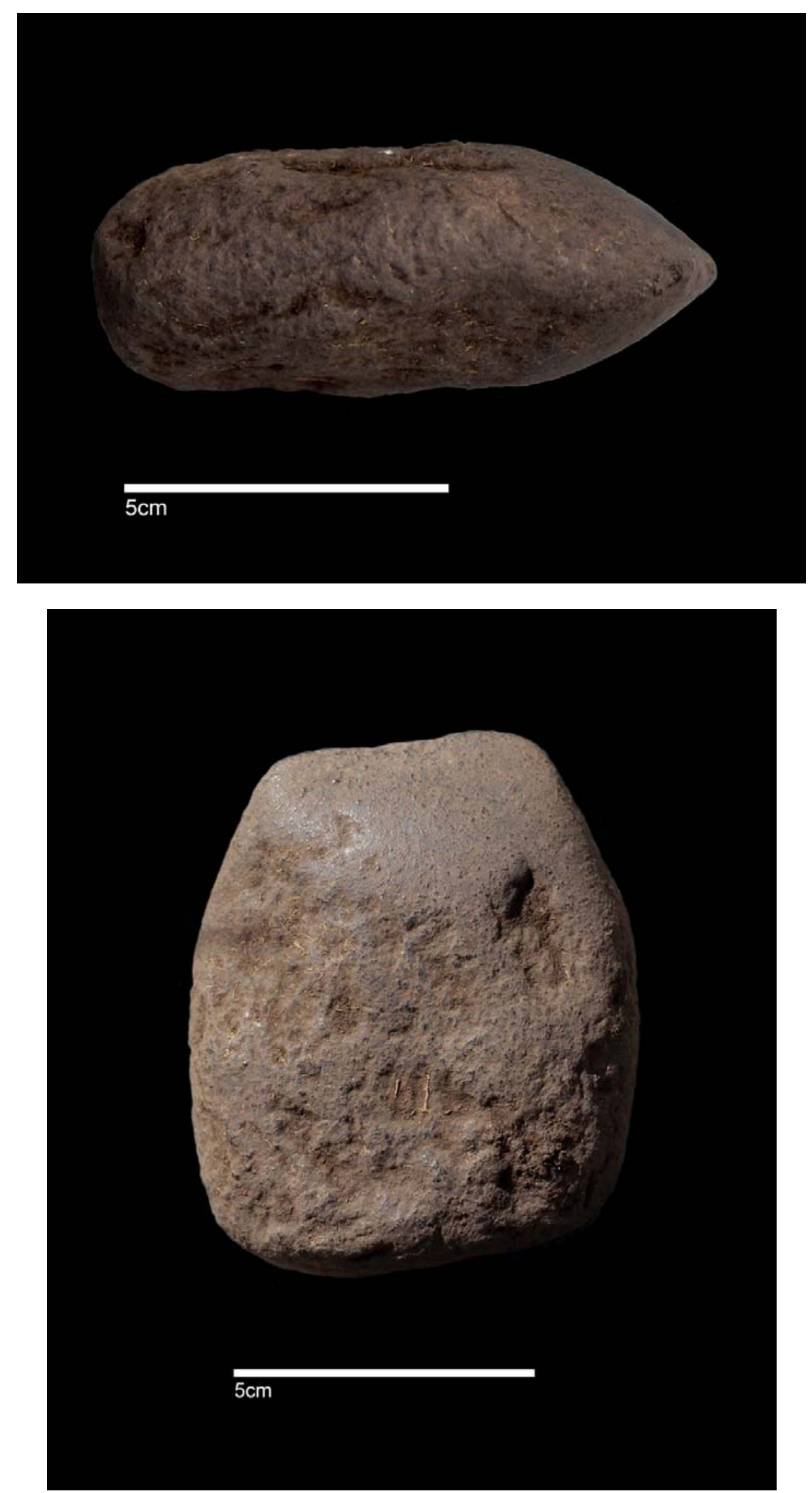

Figure 4. Edge-ground stone axe from Wathayn, Weipa (Photographs: Tim Mackrell). 
The Weipa region does indeed contain little or no suitable raw materials for the manufacture of stone artefacts as early scholars observed, with no substantial, locally accessible sources of the three dominant raw materials quartz, silcrete, and mudstone with the exception of some poor quality quartz cobbles and isolated silcrete cobbles found in water courses. Given the quantities of stone artefacts found, it seems likely that much of the raw material for artefact manufacture came from sources located to the east of the current survey zones although the precise location of these sources remains unknown. The reliance on imported raw material, probably transported as nodules as indicated by the abundance of cores in the assemblages as well as the cortex ratio and volume ratio results, possibly led to differences in the proportions of raw materials in artefact deposits among the three subregions. However, apparently independent of raw material type, each of the three subregions shows differences in the degree of reduction intensity but consistency within subregions. The lowest number of flakes per core occurs in the southern subregion and the highest occurs in the central subregion with remarkable consistency within each of the subregions. These results may indicate a yet understudied, subregional difference in landscape use by Aboriginal populations possibly reflecting different settlement movements between areas, with more abundant raw material to the east, and the Albatross Bay estuarine environment and/or subregional differences in the tasks and therefore potentially the resources exploited using stone artefacts. At present, the data needed to test these interpretations are lacking since little information exists about raw material exploitation east of the Weipa survey zones and the nature of any differences in resource availability is yet to be documented.

One feature found in all of the subregional assemblages is the high proportion of cores relative to the number of flakes. In addition, many of the silcrete cores are relatively large and retain considerable cortical surface area. Complete flakes show considerable variability in size. However, large flakes are present, many of which also retain cortex. These results suggest a relatively low intensity of core reduction and the abandonment of some large flakes with much of their utility still intact. Both the cortex ratio values and the calculations of core and flake volume indicate much the same thing although the silcrete cortex ratio suggests the transport of more flakes than the two other raw materials. With the exception of silcrete, relatively few flakes were removed from cobbles and much of the stone volume remains in the cores. These findings are unexpected given the near-absence of suitable raw material sources within the local area. In other areas of Australia, low raw material abundance led to heightened levels of core reduction. Bird and Frankel (2001), for example, described assemblages composed of very small flakes and cores from Koongine Cave. Conversely, work in western New South Wales, where raw material is abundant, indicates the abandonment of cores that could have been flaked further, together with the removal of large, cortical flakes (e.g. Holdaway and Fanning 2014; Shiner 2008). If raw material was rare, then there might be an expectation for raw material conservation, leading to the greater flaking of cores and the removal of large flakes and potentially the core itself. However, this does not appear to be the case within the Weipa region at least for mudstone and quartz artefacts, based on the surface scatters identified and the subregional level of analysis considered here. The cortex ratio results together with the volume calculations and the form of the cores themselves suggests flaking occurred in place with most of the products of reduction remaining in the surface scatters (except for silcrete).

The likely sources of raw materials occur further to the east and indicate the expenditure of effort to procure and transport lithic raw materials over distances into the Weipa region or possibly exchange relationships with eastern populations. The relative abundance of cores suggests transport as nodules rather than as flakes, in contrast to some other areas of Australia (e.g. Douglass et al. 2008). If so, nodule transportation occurred over distances that may have prevented immediate resupply in the event of raw material exhaustion during reduction. Despite this, the abandonment of large cortical cores suggests that realisation of the reduction potential of the transported nodules was not necessary. This may indicate that other aspects of socio-economy drove decisions concerning core reduction intensity. The data reported here all come from areas targeted because of mining operations. Testing the interpretations proposed would require documenting the composition of stone artefact assemblages located closer to the raw material source areas to determine whether such areas show evidence for raw material acquisition and as noted above, determining the extent of the assemblages identified on the bauxite plateau.

One way to develop an understanding of the apparent lack of economisation of raw material in lithic-poor environments is to consider the nature of the source material as well as its destination. If people moved into the Weipa area bringing with them raw material in the form of nodules the material they carried may have come from areas where raw material was both relatively more abundant and easily located. If these places were considered reliable raw material sources, then the abandonment of only partially worked cortical cobbles in the Weipa region might make sense. Whatever the socioeconomic decisions associated with raw material transport or exchange, the ease of access to resupply may have meant that there was no need to utilise the transported material to the fullest extent possible. In this way, the economics of stone artefact acquisition may act as a proxy for the scale and regularity of landscape use itself related to a range of cultural practices.

The bauxite plateau is marked by distinct wet and dry seasons. However, numerous spring-fed creeks and swamps are present, meaning that freshwater is both predictable in location, abundant, and available to some extent all year round. Therefore, movement by Aboriginal people in the past may not have been spatially constrained around zones with particular resources. Environmental predictability may have meant that particular resource areas were well known but this need not have resulted in a focussed pattern of localised resource utilisation and therefore artefact deposition. It is possible that the discard of underutilised raw materials as partial cortical nodules in these contexts, as well as the low density of stone artefacts in general, reflected a low opportunity for failure to find resources to exploit at localities easily revisited. These suggestions will require additional fieldwork and analysis to either verify or reject.

Easily accessible, distant raw material sources may explain the lack of raw material optimisation but not the small sizes of the assemblages in the Weipa region. The largest three individual assemblages from each of the subregions only number a few hundred items each. However, low numbers of 
stone artefacts may in part reflect the complex nature of local geomorphic environments in which the stone artefact discovery occurred. Within the Weipa region, subtle shifts in surface conditions may have substantial impacts upon artefact visibility. For example, stone artefacts assemblages on the black soil surfaces around swamps in the central subregion are subject to submersion during the wet season. Above the flood zone, artefacts are visible only on ironstone surfaces, and seasonal differences in visibility influence the ability to detect even these stone artefacts. Moving a few meters away from ironstone surfaces can reduce visibility to virtually zero because of vegetation and leaf litter cover. Therefore, while the visible stone artefact assemblages are small in number, they may represent only a sample of a much larger, low density or otherwise, non-visible artefact distributions. It is interesting to recall Bailey's (1993) calculation of the total number of stone artefacts at Kwamter based on the density of recovered artefacts during excavation. The estimated 19,500 artefacts is two orders of magnitude different in size compared to the numbers in the largest surface scatters reported here based on systematic survey. Despite the intensity of the systematic surveys undertaken related to mining operations, substantial numbers of artefacts may remain undiscovered in the Weipa region and the analysis results presented here need to be interpreted with this in mind.

Finally, it is important to comment on the presence of edge-ground stone axes since these were previously thought to be largely absent from the area (Sutton 1994). Their presence in the Weipa region suggests that their use may have extended throughout Cape York, in addition to their longestablished presence in the Laura area to the south (Morwood and L'Oste-Brown 1995; Morwood and Trezise 1989).

\section{Conclusion}

The analysis of western Cape York lithic assemblages demonstrates a number of unexpected patterns for stone tool manufacture and use in a region poor in raw material. We have shown that, based on systematic survey, stone artefacts are relatively common and widely dispersed across the Weipa region, albeit in assemblages largely made up of small numbers of items. This in itself is a significant finding that changes our understanding of the character of the archaeological record of the region dominated by shell mounds. Importation of cortical nodules, often discarded after only partial decortification as cores, may indicate a predictability of movement, with few environmental constraints that encouraged people to return regularly to locations with abundant and accessible raw material or establish exchange relationships with others who had access to these materials. The investigation of lithic raw material procurement and use in the likely areas to the east of the current study zone should be a priority of future lithic studies in the region as should the expansion of the number of assemblages of artefacts across the bauxite plateau as a result of future surveys. While interpretation at present is limited by the nature of the samples available for study, the results presented here indicate interesting patterns worthy of future investigation.

\section{Acknowledgements}

We would like to thank the traditional owners from the 11 groups whose land makes up the western Cape York region covered by this paper, and the Western Cape Communities Coordinating Committee and the Ely Coordination Committee. Many of the traditional owners have spent hours searching for stone artefacts during assessment surveys. These surveys were undertaken as part of Rio Tinto's cultural heritage management program. We would also like to thank the following archaeologists who at one time or another discovered stone artefacts during these surveys: Mick Morrison, Jamie Reeves, Grant Cochrane, Nicky Horsfall, Andrew Collis, Richard Woolfe, Ben Keyes, Eleanor Cooper, Alex Walter, Shezani Nasoordeen, Siobhan Walker, Daryl Wesley and Cameo Dalley. Kasey Allely read and commented upon an earlier version of the paper. Briar Sefton drew Figure 2 and Tim Mackrell took the photographs in Figure 4.

\section{References}

Bailey, G.N. 1972 Interim report to the Australian Institute of Aboriginal Studies on the Investigation of Shell Mounds at Weipa. Unpublished report to Australian Institute of Aboriginal Studies, Canberra.

Bailey, G.N. 1975 The Role of Shell Middens in Prehistoric Economies. Unpublished $\mathrm{PhD}$ thesis, University of Cambridge, Cambridge.

Bailey, G.N. 1977 Shell mounds, shell middens, and raised beaches in the Cape York Peninsula. Mankind 11(2):132-143. https://doi.org /10.1111/j.1835-9310.1977.tb01175.x

Bailey, G.N. 1993 Shell mounds in 1972 and 1992: Reflections on recent controversies at Ballina and Weipa. Australian Archaeology 37:1-18. https://doi.org/10.1080/03122417.1993.11681491

Bailey, G.N. 1999 Shell mounds and coastal archaeology in northern Queensland. In J. Hall and I.J. McNiven (eds), Australian Coastal Archaeology, pp.105-112. Research Papers in Archaeology and Natural History 31. Canberra: Archaeology and Natural History Publications, Research School of Pacific and Asian Studies, Australian National University.

Barkley, R., G. John, J. Shiner and M. Wrigley 2009 Collaboration and innovation in the management of cultural landscapes in mining contexts, western Cape York, far north Queensland. Historic Environment 21(3):7-15.

Bird, C.F.M. and D. Frankel 2001 Excavations at Koongine Cave: Lithics and land-use in the terminal Pleistocene and Holocene of South Australia. Proceedings of the Prehistoric Society 67:49-83. https://doi.org/10.1017/S0079497X00001614

Cribb, R. 1986 A preliminary report on archaeological findings in Aurukun Shire, western Cape York. Queensland Archaeological Research 3:133-158. http://dx.doi.org/10.25120/qar.3.1986.185

Davies, B. and S.J. Holdaway 2018 Windows on the past? Perspectives on accumulation, formation, and significance from an Australian Holocene lithic landscape. Mitteilungen der Gesellschaft für Urgeschichte 26:125-152.

Dibble, H.L., U.A. Schurmans, R.P. Iovita and M.V. McLaughlin 2005 The measurement and interpretation of cortex in lithic assemblages. American Antiquity 70(3):545-560. https://doi.org $110.2307 / 40035313$

Douglass, M.J., S.J. Holdaway, P.C. Fanning and J.I. Shiner 2008 An assessment and archaeological application of cortex measurement in lithic assemblages. American Antiquity 73(3):513526. https://doi.org/10.1017/S0002731600046849

Douglass, M.J., S.J. Holdaway and P.C. Fanning 2017 Selected samples: The nature of silcrete adzes in the formation of Australian stone artefact assemblages. Journal of Archaeological Science: Reports 15:578-586. https://doi.org/10.1016/j.jasrep.2017.04.013 
Eggleton, R.A. and G. Taylor 2008 Effects of some macrobiota on the Weipa bauxite, northern Australia. Australian Journal of Earth Sciences 55:s71-s82. https://doi.org/10.1080/08120090802438258

Hiscock, P. 2002 Quantifying the size of artefact assemblages. Journal of Archaeological Science 29(3):251-258. https://doi.org /10.1006/jasc.2001.0705

Holdaway, S.J. and P.C. Fanning 2014 Geoarchaeology of Aboriginal Landscapes in Semi-Arid Australia. Sydney: CSIRO Publishing.

Holdaway S.J., P.C. Fanning, F. Petchey, K. Allely, J.I. Shiner and G. Bailey 2017 Temporal variability in shell mound formation at Albatross Bay, northern Australia. PLOS ONE 2(8):e0183863. https://doi.org/10.1371/journal.pone.0183863

Holdaway, S., J. Shiner and P. Fanning 2005 Hunter-gatherers and the archaeology of discard behavior: An analysis of surface stone artifacts from Sturt National Park, western New South Wales, Australia. Asian Perspectives 43(1):34-72. https://doi.org/10.1353 $\underline{\text { lasi.2004.0005 }}$

Holdaway, S. and N. Stern 2004 A Record in Stone: A Study of Australia's Flaked Stone Artefacts. Melbourne and Canberra: Museum Victoria and Aboriginal Studies Press.

Morrison, M. 2003 Old boundaries and new horizons: The Weipa shell mounds reconsidered. Archaeology in Oceania 38(1):1-8. https://doi.org/10.1002/j.1834-4453.2003.tb00516.x

Morrison, M. 2010 The Shell Mounds of Albatross Bay: An Archaeological Investigation of Late Holocene Production Strategies near Weipa, North Eastern Australia. Unpublished $\mathrm{PhD}$ thesis, Flinders University, Adelaide.

Morrison, M., D. McNaughton and J. Shiner 2010 Mission-based Indigenous production at the Weipa Presbyterian Mission, western Cape York Peninsula (1932-66). International Journal of Historical Archaeology 14(1):86-111. https://doi.org/10.1007/s10761-0090096-8

Morwood, M.J. and S.L'Oste-Brown 1995 Chronological changes in stone tool technology. In M.J. Morwood and D.R. Hobbs (eds), Quinkan Prehistory: The Archaeology of Aboriginal Art in SE Cape York Peninsula, Australia, pp.127-132. Tempus 3. St Lucia, QLD: Anthropology Museum, University of Queensland.

Morwood, M.J. and P.J. Trezise 1989 Edge-ground axes in Pleistocene Greater Australia: New evidence from S. E. Cape York Peninsula. Queensland Archaeological Research 6:77-90. http://dx.doi.org/10.25120/qar.6.1989.138

Phillipps, R.S. and S.J. Holdaway 2016 Estimating core number in assemblages: Core movement and mobility during the Holocene of the Fayum, Egypt. Journal of Archaeological Method and Theory 23(2):520-540. https://doi.org/10.1007/s10816-015-9250-2
Shiner, J.I. 2008 Place as Occupational Histories: An Investigation of the Deflated Surface Archaeological Record of Pine Point and Langwell Stations Western New South Wales, Australia. British Archaeological Reports International Series 1763. Oxford: Archaeopress.

Shiner J.I., P.C. Fanning, S.J. Holdaway, F. Petchey, C. Beresford, E. Hoffman and B. Larsen 2013 Shell mounds as the basis for understanding human-environment interaction in far North Queensland, Australia. Queensland Archaeological Research 16:65-91. http://dx.doi.org/10.25120/qar.16.2013.224

Shiner, J.I., S.J. Holdaway, H. Allen and P.C. Fanning 2005 Understanding stone artefact assemblage variability in late Holocene contexts in western New South Wales, Australia: Burkes Cave, Stud Creek and Fowlers Gap. In C. Clarkson and L. Lamb (eds), Lithics Down Under: Australian Perspectives on Lithic Reduction, Use and Classification, pp.67-80. British Archaeological Reports International Series 1408. Oxford: Archaeopress.

Shiner, J., S. Holdaway, H. Allen and P. Fanning 2007 Burkes Cave and flaked stone artefact assemblage variability in western New South Wales. Australian Archaeology 64:35-45. https://doi.org $\underline{10.1080 / 03122417.2007 .11681847}$

Shiner, J. and M. Morrison 2009 The contribution of heritage surveys towards understanding the cultural landscape of the Weipa bauxite plateau. Australian Archaeology 68:52-55. https://doi.org/10.1080 /03122417.2009.11681890

Sutton, P. 1994 Material culture traditions of the Wik peoples, Cape York Peninsula. Records of the South Australian Museum 27:31-52.

Sutton, P. 2010 The logic of Wik camping, north Australia. In K. Hardy (ed.), Archaeological Invisibility and Forgotten Knowledge: Conference Proceedings, Lódź, Poland, 5th-7th September 2007, pp.91-107. British Archaeological Reports International Series 2183. Oxford: Archaeopress.

Wright, R.V.S. 1971 Prehistory in the Cape York Peninsula. In D.J. Mulvaney and J. Golson (eds), Aboriginal Man and Environment in Australia, pp.133-140. Canberra: Australian National University Press.

Citation: Shiner, J., S. Holdaway P. Fanning 2018 Flaked stone assemblage variability across the Weipa region of western Cape York Peninsula, Queensland. Queensland Archaeological Research 21:1-11. https://doi.org/10.25120/qar.21.2018.3636 
